\title{
The use of social science methods in agricultural research: the case of late transplanting of rice in the Dominican Republic
}

\section{F. DOORMAN*}

Department of Rural Sociology of the Tropics and Subtropics, Wageningen Agricultural University, Hollandseweg 1, NL 6706 KN Wageningen, Netherlands

Received 8 June 1988; accepted 5 January 1989

\begin{abstract}
This article aims to show how social science methods can be combined with agronomic research to yield information directly relevant to the development of agricultural technology for small farmers. First, problem identification and definition are worked out through reconnaissance and case studies. Then, quantitative estimates of the prevalence and impact of those problems can be obtained through the execution of a survey and trials. The combination of qualitative and quantitative methods can result in a substantial change in outlook on a specific problem, as is indicated for the case of rice transplanting in the Dominican Republic.
\end{abstract}

Keywords: adaptive research, farming systems research, social science methods, multi-disciplinary agricultural research, technology development, small farmers, late transplant of rice, Dominican Republic

\section{Introduction}

In recent years, there has been a growing recognition that the development of new agricultural technology for small farms in the Third World should not be the exclusive domain of biological scientists. As a result, the input of such disciplines as economics, sociology and anthropology is now considered of mayor importance in understanding the complexities of small-scale farming (Fresco, 1984). Currently, the most well-known multi-disciplinary approach to developing agricultural technology for small farmers is Farming Systems Research (FSR). The objective of FSR, as described by Gilbert et al. (1980), is 'to increase productivity of farming systems given their constraints and potential and taking into account the farm household's private goals'. The core of FSR is its systems perspective: rather than focussing on a single crop or an aspect of its cultivation, agricultural activity is studied within the context

\footnotetext{
* Present address: Proyecto UNA-ICAU, Escuela de Ciencias Agrarias, Universidad Nacional, Apartado 86, Heredia, Costa Rica.
} 


\section{F. DOORMAN}

of the physical, biological and socio-economic conditions that determine the farm families' goals, access to resources and decision-making (Shaner, 1982). Initially, the social scientists that studied the socio-economic aspects of small farm systems were almost exclusively economists. This led, on the one hand, to a notable lack of emphasis on the analysis of social and cultural factors influencing farmer decisionmaking (Garrett, 1984). On the other hand, in the area of method it has resulted in a strong emphasis on quantitative research, usually through surveys, and little attention for qualitative analysis.

Since the early 1980's there has been a growing interest in increasing the role of sociology and anthropology in agricultural research for small farmers (see for instance Gladwin, 1983; Horton, 1984; Rhoades, 1984; de Walt, 1985; Tripp, 1985). One approach, building on FSR, but incorporating methodological and conceptual elements of social sciences other than economics, is what in this article will be called 'adaptive agricultural research' (Box et al., 1987). Adaptive research, more so than FSR, puts emphasis on farmer participation in technology development. It does this not only through direct involvement of farmers in on-farm agronomic research, but also by basing the new technology as much as possible on indigenous technical knowledge. Other important elements of adaptive research are the analysis of the influence of social, cultural and political factors on the farming system, and a historical perspective on the decision-making therein. Also, adaptive research involves qualitative analysis of farmer decision-making and the motivations, perceptions and aspirations that lie behind it. In the area of method, qualitative case study research is added to quantitative survey research. As will be shown in this article, both these social science methods are used not only for studying what is normally considered the domain of the social sciences, but also for analysing specifically 'technical' problems.

In this article, a specific topic of rice research in the Dominican Republic, that of the late transplanting of rice seedlings, will be used to illustrate how adaptive research, through combining the social science methods of case study and survey interviewing with agronomic research, can be employed to yield information relevant to the development of agricultural technology for small farmers. Thereby, emphasis will be put on the methodological contribution of the social sciences to the study of agronomic problems, rather than on the analysis of the social, cultural and historical factors referred to in the above. We will start with a brief description of the setting, the rice-producing area around the town of Nagua in the Dominican Republic. This will be followed by an introduction to the methodology used. Then, the identification and definition of the problem of late transplanting will be discussed. Subsequently, some quantitative estimates of the prevalence and impact of the problem, as obtained in the survey and agronomic research, are presented. Finally, some general conclusions are formulated on the methodology used, with particular emphasis on the social science contribution.

\section{Setting}

Research took place in the Land Reform Project of El Pozo, in the north-east of the 
Dominican Republic. The area has a tropical lowland climate, with an average annual precipitation of some $2000 \mathrm{~mm}$, with peaks in May and November. In overall terms, soils, although low in phosphate, are fertile, with high organic matter and potassium contents. Rice cultivation is almost entirely irrigated; however, due to an insufficient water management infrastructure, many zones face irrigation problems, especially during dry spells.

The El Pozo project is administered by the Dominican Land Reform Agency, the Instituto Agrario Dominicano (IAD). Other government institutions supply services such as the upkeep and expansion of the irrigation and drainage systems, credit, and extension. Also, there is a local experimental station of the national rice research institute CEDIA (Centro de Investigaciones Arroceras).

Land Reform farmers occupy plots between 1.5 to 4 ha in size, with an average of ca. 2.8 ha (Doorman, 1986). Ca. $85 \%$ of the about 1300 beneficiaries that are registered as actively engaged in commercial rice production use credit from the staterun Agricultural Credit Bank (Banco Agricola). Fertilizers, post-emergent herbicides, insecticides and modern semi-dwarf varieties developed by CEDIA are widely used.

\section{Methodology}

Research was initiated with a reconnaissance, in which information on the research area in general, and cropping systems involving rice in particular was collected. Apart from interviewing key-informants such as local government officials, some 60 interviews with farmers randomly encountered in different parts of the research area served both to obtain some preliminary insight in rice cultivation practices and to select informants for the second research phase, the case studies. These consisted of extensive interviews with 18 of the most knowledgeable farmers identified in the reconnaissance, with a strong focus on the 'how's' and why's' of decisionmaking in farm management. This resulted in a wealth of qualitative information on every aspect of rice farming, including the management of land, labour and capital, the farmers' perception of farmers' organizations and government institutions, and farmer goals, preferences and aspirations. Most importantly, a number of specific problems in rice farming were encountered, along with the adaptations farmers made to counter the negative effects of these problems on yields.

Since the information gathered in the case studies could not be considered representative for the El Pozo farmer population at large, the next step in the research process was to evaluate a limited number of the topics encountered in the case studies in a survey applied to a $10 \%$ sample of the reform project's registered beneficiaries. That way it was possible to obtain statistically meaningful estimates of key variables such as the number of farmers affected by specific problems identified in the case studies, resulting yield losses, and the frequency of the use of adaptations. At the same time, agronomic research was initiated on one of the problems identified in the case studies, i.e. late transplanting. The objective of these 'adaptive trials' was to establish the impact of late transplanting on yields, and the effect of farmer adaptations on countering yield losses. 


\section{Problem identification in the case studies: late transplanting}

In the case studies it was found that the frequently occurring shortages of irrigation water and machinery for land preparation often lead to delays in the transplanting of seedlings. To be able to transplant as soon as the rainy season starts, usually midApril, farmers establish their seedbeds in March or sometimes even in February. The idea is to transplant the seedlings when they are about 45 days old, which is considered the optimum age by most farmers. However, water shortages and the lack of tractors in the zone cause delays in land preparation or inundating the land for sowing. As a result, seedlings may be in the seedbed for anywhere from 60 to over a 100 days before being transplanted. Most farmers interviewed in the case studies testified that the use of seedlings of over 50 days old reduced yields, as a consequence of lesser tillering of older seedlings. However, most informants also claimed they could counteract this problem by increasing plant density, the application of a higher than normal dose of NPK fertilizer to increase tillering, or planting the seedlings in an inclined rather than upright position. The latter practice was asserted to result in root formation from the second and third node of the seedling. Thus, out of one seedling several plants would evolve, each with its own root system and tillers.

\section{The view of rice specialists and extension agents}

The research team also verified what agronomists and extension agents had to say about late transplanting. It appeared that the use of seedlings older than 45 or 50 days was condemned almost unanimously because it leads to unacceptable yield reductions. It was not very clear where this idea had originated. It appeared to be an extrapolation of a recommendation that 30 to 40 days is the optimum age for transplanting. This advice appeared both in teaching materials for extension agents and in a leaflet published by the Ministry of Agriculture for distribution among farmers. However, in research done by a CEDIA investigator in the early seventies (CEDIA, 1974) the use of seedlings of 70 days old of the long-cycle (5 to 6 months) cultivar Juma 57 had resulted in yields that were actually higher than the yields of 35day-old seedlings. Only in 1983, several years after it was formulated, was the above recommendation confirmed by research with a medium-cycle (4 months) cultivar (Pérez Rodríguez, 1983).

\section{Literature on late transplanting}

Both as a preparation to agronomic research and to shed some light on the possible origin of the seedling age recommendation used in the Dominican Republic, part of the literature on the late transplanting of rice was consulted. The International Rice Research Institute, in a growth and yield test involving 29 cultivars, reports that only four yielded more than 3 tonnes per hectare when transplanting was delayed until 60 days after seeding. For IR 36, an early cultivar widely sown in the Philippines, declines in yields were as much as 83 and $90 \%$ in comparison with 40 - and 
20-day seedlings, respectively (IRRI, 1985). Other authors, e.g. Sharma et al. (1979), Rajendra \& Reddy (1981), Padalia (1981), and Ghosh (1982), all report significant yield reductions with the use of 55- to 65-day-old seedlings. On the other hand, normal yields with old seedlings are mentioned by Shahi \& Gill (1977), Kailasam \& Ramamurthi (1978), and Murty \& Sahu (1978). Most notable is the study of Kailasam \& Ramamurthi, in which even 90-day-old seedlings showed no significant yield reductions.

From the literature it appears that the best results with the use of old seedlings are obtained with long-cycle cultivars. As some of the cited authors indicate, the effects of late transplanting do not depend on the age of the seedlings measured in days, but on the 'biological' age, that is the stage of development of the rice plant. Apart from genetically determined characteristics, particularly cycle length, the biological age is also influenced by environmental factors, especially climatological conditions and water supply. For example, Purseglove (1985), indicating the relationship between water management and seedling age, recommends to transplant seedlings from a flooded seedbed before they are 40 days old whereas seedlings from a dry seedbed can be used up to an age of 70 to 80 days.

Finally, it is interesting to look at what the literature has to say about ways to counteract yield reduction. Hagens (1986) cites Sharma et al. (1979) and Nair et al. (1981), who both indicate increasing plant density. Nair et al. (1981) suggest increasing nitrogen application, while Ishii (1977) recommends transplanting in an inclined position to enhance tillering at the higher nodes (all citations from Hagens, 1986).

From the above, it seems probable that the 45 day recommendation used by Dominican rice experts is derived at least partly from the Asian work on late transplanting with IRRI's new dwarf and semi-dwarf cultivars. However, in formulating the 45 day recommendation apparently no account was taken of the effects of cycle length or varying environmental conditions on seedling development. The result has been a rigidly formulated recommendation uniformly applied in a wide variety of settings and circumstances.

\section{Follow-up studies: survey and agronomic research}

After pinpointing the problem in the case studies, late transplanting was selected as one of the topics for further research in the subsequent phases of the Adaptive Agricultural Research project: a survey among a representative sample of the El Pozo project's population, and adaptive trials. The reasons for selecting this particular topic were several. First, here was a problem that, both among farmers and rice specialists, was claimed to be fairly widespread. Then, the specialists maintained that it had a significant impact on yields; some farmers, however, claimed that these yield reductions could be counteracted by specific practices. The survey was directed at obtaining quantitative estimates of the number of farmers affected by late transplanting and the frequency of the use of adaptations. Also, some first crude estimates were expected of the impact of the problem on yields. The trials were aimed at obtaining more exact quantitative estimates of yield losses, and evaluating the ef- 
fectiveness of some of the farmers' adaptations. The final result was expected to be useful in developing more specific recommendations for farmers faced with late transplanting. These recommendations should be based on the most effective solutions for the problem applied by farmers. Thus, indigenous technology used by what was assumed to be an elite group of farmers, namely the informants selected for the case studies, would so become available for much larger groups.

Survey results confirmed the frequency of late transplanting: of 177 harvests taken into account, one-third was sown with seedlings of over 45 days old, and in ca. $13 \%$ of all cases seedlings older than 60 days were used. On the other hand, the farmers' adaptations encountered in the case studies were much more widespread than expected: only 5 out of 91 respondents affected by the problem reported not doing anything specific when transplanting late. The most frequently encountered adaptation was increasing plant density: 56 respondents $(61.6 \%)$ claimed either to plant more seedlings per hill or to reduce distances between hills, or did both. As far as yields were concerned, in accordance to farmers' claims, the difference between the average yields of crops planted in time ( 3.55 tonnes per hectare) and those of crops planted late (3.46 tonnes) were not found to be statistically significant (at the $5 \%$ level; the total number of harvests taken into account was 150 ). The interesting question that remained was whether the absence of yield reductions was a result of farmers' adaptations, or that the yields obtained with old seedlings would have been equal to those of crops transplanted in time anyway, regardless of farmers' practices.

To obtain an answer to this question, that is to say, to obtain more exact estimates of yield losses resulting from late transplanting both with and without adaptations, agronomic research was undertaken by a team of Dominican agronomists and Dutch and Dominican agronomy students. A first series of three trials, executed by agronomy students under supervision of rice specialists from CEDIA in the Central Valley region of the Dominican Republic, used seedlings of 40,60 and 80 days old of the long-cycle cultivar. Yield results were highest for the 60-day-old seedlings, and, even more remarkable, no statistically significant differences were found between the yields of the 40- and 80-day-old seedlings (Rosario \& Rosario, 1984; Columna \& Cedano, 1984). In a second series of trials (Hagens \& Doorman, 1985), the performance of 'young' seedlings ( 36 to 60 days old) was compared with that of 'old' ones ( 75 to 116 days) in the El Pozo region. Four trials were laid out on farmers' fields and three on the local experimental station of the national rice research institute CEDIA. In all seven trials the cultivar Juma 57 was used; in addition, in two of the three on-station experiments one medium-cycle cultivar, ISA 21, and two promising new medium-cycle lines developed at CEDIA were evaluated. Significant yield reductions occurred in two of the four on-farm trials, and in the onstation trial with the 116-day seedlings. Surprisingly, in the latter case the reduction was only ca. $17 \%$. Interestingly, both on-farm trials resulting in significant yield reductions (of ca. 25 and $30 \%$, respectively) were seriously affected by drought, which led to the hypothesis that adverse conditions may have a stronger effect on older seedlings than on younger ones. But in four trials executed under non-stress conditions, no significant differences were found between the 'young' seedlings of 
$36,38,47$ and 60 days, and the 'old' ones of $80,73,106$ and 80 days, respectively.

On the other hand, in none of the trials any indication was found that the farmer adaptations tested, i.e. the increase of plant density and, in one trial, applying extra fertilizer, had any effect on yields. In one of the two on-farm trials affected by drought the yields obtained with older seedlings were less in spite of increased plant density, while in the other trials yields remained stationary both with and without this specific farmer adaptation. In the other on-farm trial affected by drought, it was found that extra fertilization did not have counteracting effects on yield reductions either. It also became clear that in those cases where significant yield reductions were found, these were due not to decreased tillering and a resulting lesser number of panicles, but rather to smaller-sized panicles. Apparently, this weight loss per panicle could not be compensated by augmenting the number of panicles through increased plant density.

The first conclusions that can be drawn from these findings is that more research is needed to establish more clearly which factors influence the late transplanting of rice seedlings and to what extent. The apparently complex interactions between cycle length, environmental conditions and seedbed treatment needs to be explored more thoroughly if relevant recommendations are to be developed for varying circumstances.

A second conclusion is that the data obtained indicate that under certain circumstances the use of seedlings older than 45 days is indeed feasible. This implies that the current recommendation given by Dominican extension agents should be adjusted to fit specific circumstances. The research suggested in the above should yield the necessary indications as to what those circumstances are. The adjustment of the current recommendation is all the more important since extension agents may advise the Agricultural Credit Bank to withhold credit to farmers who transplant late. Thus, the latter are deprived of credit for the rest of the production cycle, or will incur considerable costs by having to make a new seedbed or having to buy seedlings elsewhere.

\section{Conclusions}

The aim of this article was to show how methods of the social sciences, i.e. farmer interviewing in case studies and surveys, can be combined with agronomic research to yield insight into crop production problems faced by small farmers. The specific social science contribution consists, in the case studies, of making clear small farmer production conditions, the problems resulting from those conditions, and farmers' adaptations to those problems. In the survey research, quantitative estimates can be obtained of the frequency and impact of the problem, which will help determine the potential pay-off of an agronomical research program directed at diminishing the negative effects. Case studies in particular can be a quite efficient and cost-effective instrument, since a limited number can be executed within a couple of weeks, yielding a host of high-quality information on the intricacy of small-scale farming problems. 
It should be emphasized that systematic and in-depth interviewing can be of particular value in identifying occasionally occurring problems such as late transplanting. As such, it may be more suited for problem identification than the more classic forms of agronomical problem identification, i.e. observation through field visits and exploratory trials. Of course, it is not suggested here that observation should be substituted by interviewing; indeed, an essential element of case studies is making a visit to the farmer-informants' fields. The argument is for combining agronomical and social science methods by an approach based on intensive interviewing of farmer-informants on the one hand and agronomic research on the other. Thus, a more complete picture can be obtained of the complex problems of small-scale farming as a base for the development of technology adapted to small-farm conditions.

\section{References}

Box, L. et al., 1987. Adaptive Agricultural Research Project, 1981-1985: The Dominican Republic: collected reports and papers. IDC Microform Publishers, Leiden/Department of Rural Sociology, Wageningen Agricultural University, Netherlands.

CEDIA, 1974. Experimento sobre la edad de las plántulas, fertilización y marcos de plantación. Memoria Anual 1974, p. 56-58. Secretaría de Estado de Agricultura, Juma, Bonao, Dominican Republic.

Columna Diaz, M. \& R. A. Cedano Cruzano, 1984. Efecto del número de plántulas por golpe en el rendimiento de arroz (Oryza sativa) transplantado con plántulas viejas. Graduate thesis, Instituto Superior de Agricultura, Santiago, Dominican Republic, $45 \mathrm{pp}$.

Doorman, F, 1986. Condiciones, rendimientos e ingresos en el cultivo del arroz. Resultados de una encuesta entre 242 arroceros de la Reforma Agraria en las zonas de Nagua y Mao. In: Adaptive Agricultural Research Project, 1981-1985: The Dominican Republic: collected reports and papers: C 14, IDC Microform Publishers, Leiden/Department of Rural Sociology, Wageningen Agricultural University, Netherlands, $158 \mathrm{pp}$.

Fresco, L., 1984. Issues in farming systems research. Netherlands Journal of Agricultural Science 32: 253-261.

Garrett, P., 1984. The relevance of structural variables for farming systems research. Rural Sociology 49: 580-589.

Gilbert, E. H., D. W. Norman \& F. E. Winch, 1980. Farming systems research: a critical appraisal. Michigan State University Rural Development Paper No 6, Michigan State University, East Lansing, $134 \mathrm{pp}$.

Gladwin, C. H., 1983. Contributions of decision tree methodology to a farming systems program. $\mathrm{Hu}$ man Organization 42: 146-157.

Ghosh, D. C., 1982. Effect of age of seedlings and planting density on growth and yield of rice under late planting. Madras Agricultural Journal 69: 376-380.

Hagens, P. \& F. Doorman, 1985. El transplante atrasado en el cultivo del arroz. Resultados de experimentos sobre el transplante del arroz (Oryza sativa) con plántulas mayores de 45 dias en la región de Nagua, Rep. Dominicana. Working document, Adaptive Agricultural Research Project, 1981-1985: The Dominican Republic: collected reports and papers: C 15, IDC Microform Publishers, Leiden/Department of Rural Sociology, Wageningen Agricultural University, Netherlands, $58 \mathrm{pp}$.

Hagens, P., 1986. Transplanting old rice seedlings in the Dominican Republic. Graduate thesis, Department of Tropical Crop Science, Wageningen Agricultural University, Netherlands, $37 \mathrm{pp}$.

Horton, D. E., 1984. Social scientists in agricultural research: lessons from the Mantaro Valley Project, Peru. Publication IDRC-219e, International Development Research Centre, Ottawa, 67 pp.

IRRI, 1985. Identifying rainfed rices for late transplanting. Annual Report 1984, p. 26-27. International Rice Research Institute, Los Baños, Philippines.

Kailasam, C. \& T. G. Ramamurthi, 1978. Planting date and seedling age effect on duration and yield of CO.40. Aduthuran Report 2: 51-53. 
Murty, K. S. \& G. Gahu, 1979. Effect of age of seedlings at normal transplanting on growth and yield of rice varieties. Indian Journal of Agricultural Science 49: 797-801.

Padalia, C. R., 1980. Effects of age of seedlings on the stand establishment of transplanted rice under medium and lowland conditions. Oryza 17: 139-141.

Padalia, C. R., 1981. Effect of age of seedlings on the growth and yield of transplanted rice. Oryza 18: 165-167.

Pérez Rodriguez, F., 1983. Edad óptima para transplante manual y mecanizado en variedades de arroz de portes diferentes. Centro de Investigaciones Arroceras (CEDIA), Juma, Bonao, Dominican Republic, $8 \mathrm{pp}$.

Purseglove, J. W., 1985. Tropical Crops. Monocotyledons. Longman, London, 607 pp.

Rajendra, P. \& S. N. Reddy, 1980. Nursery management studies in paddy (Oryza sativa L.). International Rice Commission Newsletter 29: 35-38.

Rhoades, R. E., 1984. Breaking new ground. Agricultural anthropology. International Potato Center (CIP), Lima, $71 \mathrm{pp}$.

Rosario Jaquez, O. R. \& R. M. Rosario Yaport, 1984. Efecto de diferentes niveles de nitrógeno en el rendimiento de arroz transplantado a diferentes edades de planta. Graduate thesis, Instituto Superior de Agricultura, Santiago, Dominican Republic, $39 \mathrm{pp}$.

Shahi, H. N. \& P. N. Gill, 1977. Quantitative relationship of grain yield and its components to age of seedlings under different dates of transplanting in rice. Indian Journal of Agronomy 22: 140-144.

Shaner, W. W., P. F. Philipp \& W. R. Schmehl, 1981. Farming systems research and development: guidelines for developing countries. Westview Press, Boulder, Colorado, $413 \mathrm{pp}$.

Sharma, G. L., R. C. Gautaume \& P. S. Bisht, 1979. Effect of seedling age and number per hill on grain yield of rice varieties. International Rice Research Newsletter 4: 19-20.

Tripp, R., 1985. Anthropology and on-farm research. Human Organization 44: 114-124.

Walt, B. R. de, 1985. Anthropology, sociology and farming systems research. Human Organization 44: 106-114. 